1 Universidade Federal do Rio de Janeiro (UFRJ), Instituto de Estudos em Saúde Coletiva (lesc) - Rio de Janeiro (RJ), Brasil. biaensp@gmail.com

2 Fundação Oswaldo Cruz (Fiocruz), Escola Nacional de Saúde Pública Sergio Arouca (Ensp), Laboratório de Avaliação de Situações Endêmicas Regionais

(Laser) - Rio de Janeiro (RJ), Brasil.

giselacardoso@ensp. fiocruz.br

3 Fundação Oswaldo Cruz (Fiocruz), Escola Nacional de Saúde Pública Sergio

Arouca (Ensp), Laboratório de Avaliação de Situações Endêmicas Regionais (Laser) - Rio de Janeiro (RJ), Brasil. Ministério da Saúde, Secretaria Executiva (SE), Departamento de Monitoramento e Avaliação do SUS (Demas)

- Brasília (DF), Brasil. Universidade Federal do Rio de Janeiro (UFRJ), Instituto de Estudos em Saúde Coletiva (lesc) - Rio de Janeiro (RJ), Brasil. betuca51@gmail.com

${ }^{4}$ Ministério da Saúde, Departamento de Economia da Saúde, Investimentos e Desenvolvimento (Desid) Brasília (DF), Brasil. margarete.oliveira@saude. gov.br

${ }^{5}$ Fundação Oswaldo Cruz (Fiocruz), Escola Nacional de Saúde Pública Sergio Arouca (Ensp), Laboratório de Avaliação de Situações Endêmicas Regionais (Laser) - Rio de Janeiro, Brasil.

marlycruz12@gmail.com

\section{O apoiador local como ator estratégico na implementação do QualiSUS-Rede: engenheiros de conexão?}

\author{
The supporter as strategic local actor at the QualiSUS-Network \\ implementation: connection of engineers?
}

Egléubia Andrade de Oliveira', Gisela Cordeiro Pereira Cardoso ${ }^{\mathbf{2}}$, Elizabeth Moreira dos Santos ${ }^{\mathbf{3}}$, Margareth Martins Oliveira ${ }^{4}$, Marly Marques $\mathrm{Cruz}^{\mathbf{5}}$

RESUMO Este artigo reflete sobre o apoiador institucional do Ministério da Saúde a partir da avaliação de implementação do Projeto QualiSUS-Rede. Utiliza-se o referencial de atores intermediários, inspirado na Teoria Ator-Rede, adaptada ao objeto do estudo. Entrevistaramse treze apoiadores, explorando-se as operações de translação e os domínios de mediação cognitivos, estratégicos e logísticos. Os resultados indicam a legitimação da função apoio como unidade organizacional, embora com pouca autonomia gerencial e financeira, diluindo a possibilidade desses atores de produzir e gerenciar conexões inovadoras para a construção de alianças, encaminhamentos e superação de conflitos e controvérsias.

PALAVRAS-CHAVE Apoio institucional. Avaliação em Saúde. Gestão em saúde.

\begin{abstract}
This paper reflects on the Ministry of Health 'institutional supporter', based on the implementation evaluation of QualiSUS-Network Project. We employed the intermediate actors theory, inspired by the Actor-Network Theory, and adapted to the study's object. Thirteen 'supporters' were interviewed to explore the relationship between the translation operations and mediation process (cognitive, strategic and logistic). The results indicate the 'supporter' as an organizational unit with a legitimate function, but with limited managerial and financial autonomy, which dilutes these actors possibility to produce and manage innovative connections to build alliances and overcome conflicts and controversies.
\end{abstract}

KEYWORDS Institutional supporter. Health evaluation. Health management. 


\section{Introdução}

Quando as conexões são contingenciadas por situações restritas, é problemático ultrapassar os limites para se descobrir que, além dessas conexões e, muitas vezes, em conflito com elas, encontra-se um possível não experimentado.

(FREIRE, 2016)

Este artigo apresenta uma reflexão sobre as práticas dos apoiadores do Projeto de Formação e Melhoria da Qualidade das Redes de Saúde - QualiSUS-Rede (QSR). $\mathrm{O}$ projeto, uma iniciativa do Ministério da Saúde (MS) em cooperação com o Banco Mundial (Banco Internacional para Reconstrução e Desenvolvimento - Bird), desenvolvido entre 2012 e 2014, surge para apoiar a organização de redes regionalizadas de atenção à saúde no Brasil. O Laboratório de Avaliação de Situações Endêmicas Regionais da Escola Nacional de Saúde Pública Sergio Arouca (Laser/ Ensp/Fundação Oswaldo Cruz - Fiocruz) conduziu uma avaliação de implementação com foco no componente 1 do projeto QSR. Essa iniciativa teve suas ações agrupadas em dois componentes finalísticos: 1. Qualificação do cuidado e organização de Redes de Atenção à Saúde (RAS); e 2. Intervenções sistêmicas estratégicas. $\mathrm{O}$ componente 1 abrangeu quinze experiências, ou subprojetos de apoio às RAS, em Regiões de Saúde, sendo dez vinculadas às Regiões Metropolitanas (RM) e cinco às regiões denominadas 'Tipo', devido às suas singularidades, a exemplo das regiões de fronteira (BRASIL, 2011B).

O balanço dos primeiros meses de execução da pesquisa avaliativa sinalizou o grau de complexidade da condução da avaliação, considerando a diversidade de cada um dos quinze subprojetos, os diferentes tipos de atores envolvidos, bem como os variados contextos organizacionais e políticos que influenciam diretamente na sua consecução (PROJETO QSR-RELATÓRIO FINAL, 2015).

Durante a avaliação, desenvolveu-se uma reflexão sobre o papel do apoiador no estabelecimento de conexões entre as partes envolvidas e os limites do exercício do apoio na ampliação da efetividade das práticas em saúde. Da mesma forma, discutiu-se o apoio institucional tal como definido no Sistema Único de Saúde (SUS), suas finalidades e atribuições, bem como as condições para o desempenho de suas funções.

\section{O QualiSUS-Rede e a função do apoiador institucional}

O Projeto QSR, em seus 15 subprojetos, envolveu diversos interesses e instâncias estaduais e municipais. No contexto de interação dos entes federados com suas singularidades locais se insere a discussão da estratégia do Apoio Institucional Integrado como forma de potencializar maior horizontalidade e cooperação nas relações interfederativas. Esse tipo de apoio busca instituir a atuação de profissionais no apoio a áreas técnicas do MS e, localmente, em estados e regiões de saúde (BRASIL, 2011B).

Uma equipe de apoiadores institucionais foi contratada para atuar especificamente no âmbito do QSR, com vistas a favorecer a implementação de suas ações. Essa equipe mereceu uma atenção especial no que se refere ao alinhamento conceitual e à capacitação para trabalhar com processos de negociação e mediação de coletivos.

Na fase inicial da avaliação, que compreendeu a análise dos subprojetos, a atuação dos apoiadores se sobressaiu por sua contribuição nos processos de elaboração dos subprojetos e, posteriormente, no acompanhamento de sua execução. Outro aspecto que se destacou foi a abrangência das competências e funções requeridas nos editais de seleção para esse profissional. 


\section{$O$ apoiador institucional: a cognição e a prática compartilhada}

A expressão 'apoiador institucional' começou a ser utilizada em 1998 para se referir à função que ultrapassa as denominações sugeridas pela Teoria Geral da Administração para as pessoas que trabalham com alguma forma de apoio às organizações, como as de assessor, consultor ou supervisor. O MS desenvolveu uma série de capacitações de apoiadores a partir de 2006 e, em 2012, reorganizou a gestão do apoio integrado, contratando e formando mais de 200 apoiadores para o Programa de Apoio Integrado (BRASIL, 2013; BRASIL, 2005; PAULON ET AL., 2014).

A fragmentação dos processos de trabalho no âmbito do cuidado em saúde é o pano de fundo dessa iniciativa. Nesse sentido, o apoio institucional foi definido como o acompanhamento qualificado do trabalho de equipes de saúde e de ofertas de estratégias para implementação das diretrizes e dispositivos da Política Nacional de Humanização (PNH). Dentre as diretrizes estabelecidas para o apoiador institucional, prevê-se que ele atue por meio da ativação de espaços coletivos, mobilizando os diferentes atores e interesses que circulam no âmbito das relações que se estabelecem - poder, afeto, saberes -, com vistas a mediar o estabelecimento de objetivos comuns e viabilizar pactuações, compromissos e responsabilidades (BRASIL, 2013). Esperava-se, ainda, que ele potencializasse a capacidade institucional no que se referia aos processos de planejamento, monitoramento e avaliação objetivando sua institucionalização no âmbito da gestão. Desse modo, esse ator pode atuar tanto na esfera institucional como na relacional ou técnico-política, podendo ser considerado um dispositivo estratégico importante para a implementação de iniciativas inovadoras no âmbito da saúde (BRASIL, 2011A).

Em relação ao Projeto QSR, coube ao apoiador atuar na promoção da articulação entre os atores técnicos e políticos das regiões envolvidas; na análise situacional das regiões; na implementação dos projetos locais; e no monitoramento e avaliação das atividades previstas, mantendo os coordenadores do QSR no âmbito do MS informados sobre ações e agendas definidas nos territórios. A participação nos Grupos Condutores (GC), responsáveis diretos pela implementação das ações em cada região, também compunha suas atribuições.

As condições para a atuação desses atores no cenário de implementação dos subprojetos não foram uniformes. $\mathrm{O}$ exercício da função de mediação entre a gestão e as práticas de atenção é um elemento de tensão dos modos de fazer e pensar a produção da saúde (CASANOVA; TEIXEIRA; MONTENEGRO, 2014). O processo seletivo desses profissionais supôs o conhecimento prévio em atividades de gestão e planejamento, além de habilidades para ações de sensibilização e enredamento e mediação de conflitos inerentes a processos institucionais. Previa ainda outras competências, dentre as quais a apropriação das concepções de rede adotadas pela estratégia ministerial a ser estimulada ou fortalecida em cada região contemplada. As contratações se deram por tempo determinado e a remuneração, por meio de produto.

$\mathrm{Na}$ condução da avaliação do QSR, o protagonismo dos apoiadores na cadeia de implementação dos subprojetos nas quinze regiões de saúde adquiriu proeminência e nos levou à reflexão que se segue.

A sociedade do conhecimento, as redes sociais e as redes de atenção à saúde na definição adotada no projeto, as RAS são organizações poliárquicas de conjuntos de serviços de saúde vinculados entre si por uma missão única, por objetivos comuns. Estas são organizadas por ações cooperativas e interdependentes que permitem oferecer atenção contínua e integral a determinada população, de forma coordenada pela atenção primária à saúde (MENDES, 2011). Nesses termos, 
contribuir para a organização de RAS saúde tornou-se o objetivo central do QSR, levando-se em conta a desigualdade de oferta e de utilização dos serviços de saúde.

A proposta de Mendes (2011) para a organização do SUS em redes instiga a discussão em torno dos três modelos de reorganização do sistema de saúde sob a ótica da economia de escala, qualidade e acesso. As redes supõem espaços de interação e conexões diretas e indiretas, conjuntos amplos de interesses nem sempre convergentes, vinculações entre diferentes atores, além de processos e tecnologias diversas. Como assinalado por Fleury e Ouverney (2007), elas apresentam algumas limitações relacionadas ao envolvimento de inúmeros atores, à lentidão na formação de consensos, além de uma possível diluição de papéis e responsabilidades, dificultando sua gestão. No campo da saúde, os sistemas de atenção tendem a oscilar entre fragmentação e integração. Nesses termos, os sistemas fragmentados hegemônicos se organizam por meio de pontos isolados que não se comunicam entre si. Por consequência, interrompem a prestação contínua das ações de atenção à saúde à população (MENDES, 2011).

Nesse caso, a lógica de sustentação é construída por um modelo em níveis de complexidade crescente, caracterizando uma hierarquização que é vigente nas concepções normativas do SUS. Em contraposição, os sistemas integrados são organizados por meio de um conjunto coordenado de pontos de atenção, viabilizando uma conformação adaptável, flexível e conectada que responde às especificidades de populações bem definidas (MENDES, 2011). Tal proposição pressupõe a estratificação dos riscos, a inclusão dos determinantes sociais intermediários e proximais nas opções, e a organização das respostas. Além disso, os sistemas integrados envolvem gestão e governança sistêmicas, considerando pontos de apoio e a logística de funcionamento das redes.

Apesar da contribuição inovadora dos modelos propostos por Mendes (2011), a sua construção não elabora em profundidade as interfaces entre os pontos de atenção, isto é, a mediação veiculada pelas conexões entre eles. A formação de alianças entre instituições, profissionais e usuários é uma questão central para a organização dos serviços de saúde, especialmente aqueles que envolvem grupos mais vulneráveis e excluídos.

O estudo das redes é considerado um campo com muitas interações oriundas das várias interseções acadêmicas e disciplinares. Nos últimos anos, Prell (2012) assinala que a concepção de redes, sob suas diferentes perspectivas, compreende uma fórmula de apropriação do mundo social. A literatura pertinente localiza o início da teoria de redes principalmente nos Estados Unidos e Inglaterra, embora Freeman, Wicks, Parmar (2004) reconheça a influência da contribuição de várias comunidades acadêmicas, incluindo França, Hungria, Holanda e outras. Assim, os estudos de rede podem ser tomados como emergindo de diferentes trajetórias disciplinares, usualmente referidas como calcadas na psicologia social, na antropologia social e na sociologia, enfatizando que contribuições analíticas recentes definem o estudo das redes como um híbrido envolvendo combinações teóricas e avanços metodológicos especialmente relacionados com a emergência da tecnologia da informação (CASTELLS; CARDOZO, 2015).

As redes são abordadas por diferentes concepções. Na literatura, são agrupadas sob a perspectiva de redes sociais ou de circuitos gráficos (PRELL, 2012). Cada um desses agrupamentos se ramifica em diferentes enfoques. Do ponto de vista sociológico, as redes são compreendidas por meio de teorias de trocas sociais e influência, particularmente enfatizando-as como configuração materializadora da integração do micro ao macro, uma das mais reconhecidas lacunas na teoria sociológica (GRANOVETTER, 1973).

Nas teorias de redes sociais, a dinâmica das conexões é apreendida por meio das operações e práticas de relações internodais, 
interorganizacionais e interpessoais. Isso não simplifica nem clarifica a variedade de enfoques teóricos adotados, mas problematiza o desafio de compreender, além da estrutura, os aspectos relacionais e processuais desse imbricamento sócio-técnico (LATOUR, 1996).

Brevemente, apresentam-se três marcos teóricos que elaboram essas mediações. Os três situam como inerente à contemporaneidade o trabalho em gerar, reproduzir e incorporar conhecimento e tecnologias, em alta velocidade, marcando como fundamental para esses processos a noção de ‘tradução' ou 'translação', ou seja, a constante incorporação de diferentes interesses, tecnologias e práticas como fruto de mediação e modulação.

Clavier et al. (2012), ao descreverem o papel do ator intermediário, enfatizam a necessidade de, para o exercício dessa tarefa, ferramentas, competências e estratégias que envolvam a capacidade de escuta, liderança, negociação, advocacy, identidade cultural e o uso de uma linguagem comum. A presença de indivíduos chamados partnership facilitators, com a capacidade de fazer a costura entre links formais e informais envolvendo as partes, é valiosa. Tal contribuição foi de grande importância para a análise desenvolvida neste artigo.

Os autores descrevem três modelos teóricos de translação que dariam suporte aos atores, os quais, no foco desta análise, são os apoiadores: Teoria da tradução do conhecimento, Bowen e Zwi (2005); Sociologia de atores intermediários, Nay e Smith (2002); e Teoria Ator-Rede (TAR), Latour (2005).

Na primeira abordagem, Teoria da tradução do conhecimento, o foco é como esta tradução ocorre entre diferentes esferas sociais. Essa perspectiva, em contraponto à concepção de transferência de conhecimento, propõe colaboração ativa entre pesquisadores e usuários em todas as etapas da pesquisa. Essa concepção refere um processo de tradução integrado, ancorado nas referências da pesquisa participativa e pesquisa-ação (GAGNON, 2011).
Na sociologia de atores intermediários há uma distinção crucial entre as dimensões estratégicas e cognitivas da intermediação no processo de produção do conhecimento, ou seja, de um lado estariam as ideias produzidas e compartilhadas, e, de outro, o manejo dos processos de negociação. Dessa maneira, enquanto uma parte estaria voltada para as práticas estratégicas vinculadas às relações de poder, a outra focar-se-ia nas práticas cognitivas que incluem o conteúdo e o sentido (CLAVIER ET AL., 2012).

Para Bruno Latour (2005), tanto a configuração da rede como sua estabilidade, sempre provisórias, são efeitos de operações e práticas, conscientes ou não, de 'translações'. A rede é um efeito relacional gerado na heterogeneidade de forças e significados. Especificamente, pressupõe, por meio das operações de translação, a criação de conexões que expressam os processos divergentes ou convergentes em relação a um elemento problematizado. Para Law e Hassard (1999), Callon e Latour (1981), as redes não são estruturas, mas materialidades relacionais. Segundo os autores, a compreensão desse objeto só é possível mediante dois pressupostos, quais sejam, o princípio da simetria e as operações de translação.

O princípio de simetria, um dos pilares da TAR, se contrapõe à clivagem entre o determinismo social e tecnológico. A TAR assume que nem a natureza nem a sociedade podem ser usadas como explicação para a resolução de controvérsias, porque só depois que elas forem resolvidas é que saberemos de que lado cada uma delas está (LATOUR, 2011). Para Latour (2011), acompanhar a trajetória instável de uma controvérsia pressupõe contabilizar a longa e heterogênea lista de elementos que possam tornar essa discordância impossível. Esses elementos podem ser humanos ou não. São denominados 'actantes' por Latour (2011).

O conceito de translação distingue quatro operações, de acordo com Callon (1986): a problematização, a motivação, o enredamento e a construção de alianças. Entende-se 
por problematização o recorte ou objeto em torno do qual um processo de divergência ocorre.

Pode ser um conceito, uma tecnologia, uma norma. Enfim, identifica o problema a ser resolvido e os atores, (actantes), relevantes. Pela operação de problematização, o ator facilitador, ou apoiador, tenta se estabelecer como ponto de passagem obrigatória entre os outros atores na dinâmica da rede, de forma a se tornar indispensável (DE LEEUW ET AL., 2008). O objetivo seria atingir uma compreensão comum a respeito de uma dada situação, apesar das diferentes posições sociais e potenciais conflitos de interesse, valores e expertises entre os actantes.

A motivação envolve as negociações estratégicas entre os actantes para alinhar os vários interesses e as respectivas identidades dentro da rede, definindo como cada um pode contribuir para a resolução dos problemas identificados. É importante que os atores envolvidos se interessem e negociem os termos de seu envolvimento (SANTOS ET AL. 2012). O ator facilitador, ou apoiador, trabalha para convencer os demais actantes da pertinência de seus respectivos papéis. $\mathrm{O}$ enredamento inclui as ações e as práticas que contribuem para estabilizar a função de cada um na rede. Nessa fase, os actantes aceitam os papéis designados para eles durante a fase de motivação (DE LEEUW ET AL., 2008).

A criação de alianças envolve a escolha de determinados actantes com grande chance de abandonar outros. No caso de inovações, os diferentes actantes são incluídos de forma a alcançar um repertório de manobras de negociações, no processo de forjar soluções inovadoras.

Apesar de as quatro operações ocorrerem de forma sequencial, o processo de translação é interativo e dinâmico, envolvendo a contínua reconciliação dos conhecimentos e interesses na medida em que as negociações e translações acontecem.

O conceito de translação, tal como desenvolvido pela TAR, enfatiza o processo de mediação e alinhamento de interesses - as ações e estratégias implantadas como forma de encontrar um terreno comum que contemple os interesses dos diferentes actantes.

Baseado na revisão dos três modelos teóricos de translação acima descritos, Clavier et al. (2012) afirmam que a translação envolve um processo abrangendo três domínios que ocorrem concomitantemente e são fundamentais para o processo:

1) Mediações cognitivas: lida com o conteúdo do conhecimento necessário - circulação do conhecimento, formalização das perguntas da pesquisa);

2) Mediações estratégicas: abrange todas as atividades, competências e ferramentas para manter o interesse das partes envolvidas; e

3) Mediações logísticas: é a capacidade de coordenação que cria as condições de parceria - marcar reuniões, conectar, consolidar as memórias etc.

\section{Metodologia}

Para a construção deste artigo, procedeu-se à revisão bibliográfica; à análise documental de relatórios periódicos elaborados pelos apoiadores para o setor competente do MS; a oficinas de acompanhamento da atuação dos apoiadores; a oficinas de validação da modelização das intervenções, entrevistas transcritas; além dos relatórios parciais e final do projeto QSR. É importante ressaltar que os relatórios contêm, além do registro descritivo das ações, a observação direta dos pesquisadores sobre a atuação e o envolvimento do apoiador com as competências requeridas.

Todo o material da pesquisa foi coletado após a apreciação de eticidade, em conformidade com a Resolução $n^{0} 466 / 2012$, que regulamenta a pesquisa com seres humanos. O projeto foi submetido ao Comitê de Ética em Pesquisa da Escola Nacional de Saúde Pública Sergio Arouca da Fiocruz e aprovado pelo parecer 213.691, de 7/3/2013. 
As análises de entrevistas gravadas e realizadas por meio de roteiro semiestruturado, apresentadas neste artigo, envolveram treze apoiadores do QSR. Cabe esclarecer que houve recusa à concessão de entrevistas em dois subprojetos. O roteiro era composto de nove blocos, compreendendo a identificação do entrevistado; o contexto político-organizacional de cada território; a participação social e de instâncias deliberativas na formulação e implementação dos subprojetos; os elementos da configuração das RAS locais; os instrumentos de gestão e governança mobilizados; a gestão de Recursos Humanos (RH) na região; a implementação das ações específicas dos subprojetos; a integração das intervenções sistêmicas; e as propostas de sustentabilidade das RAS nas regiões. As entrevistas foram realizadas no período de junho a novembro de 2014 por pesquisadores responsáveis pela condução da pesquisa avaliativa, nos locais de atuação dos apoiadores, ou seja, nas Secretarias Estaduais de Saúde (SES), com exceção de duas entrevistas concedidas durante realização de seminário sobre redes e regionalização ocorrido no âmbito da pesquisa. As entrevistas ocorreram em ambiente adequado, preservando-se a privacidade dos sujeitos envolvidos.

Além das treze entrevistas, a análise incluiu mais 17 entrevistas, sendo duas com a coordenação de gestão do projeto QSR do MS e 15 com coordenadores dos GC locais. Destaca-se que o foco da análise apresentada neste artigo centra-se nas entrevistas dos apoiadores, mobilizando-se as 17 entrevistas apenas para ampliar e aprofundar a compreensão dos sujeitos em estudo.

Procedeu-se ao exame do material transcrito utilizando como referencial a abordagem sobre a atuação de atores intermediários desenvolvida em Clavier et al. (2012), e adaptada ao objeto da avaliação. Esse plano de análise é apresentado no quadro 1.

Quadro1. Temas problematizados, operações de tradução e domínios de mediação

\begin{tabular}{lccc}
\hline \multirow{2}{*}{$\begin{array}{c}\text { Domínios de } \\
\text { mediação }\end{array}$} & $\begin{array}{c}\text { O que e como foi } \\
\text { problematizado? }\end{array}$ & $\begin{array}{l}\text { Quais e como ocorreram os } \\
\text { processos de mobilização? }\end{array}$ & $\begin{array}{c}\text { Quais e como foram } \\
\text { construídas as alianças? }\end{array}$ \\
\cline { 2 - 3 } $\begin{array}{l}\text { Cognitiva } \\
\text { Estratégica }\end{array}$ & Conhecimento, conteúdo e significado & \\
Logística & Harmonização de controvérsias e manejo dos processos de negociação \\
\hline
\end{tabular}

Fonte: Adaptado de Clavier et al (2011)

A grande diversidade de subprojetos faz dos resultados aqui apresentados apenas uma interpretação baseada em questões priorizadas no seu conjunto. Com o objetivo de sistematizar e caracterizar as conexões identificaram-se interfaces multirrelacionais entre os actantes, tais como: apoiador-apoiador; apoiador-apoiador temático; apoiador-UGP (Unidade Gestora do Projeto); apoiador-Grupo Condutor; apoiador-Conasems (Conselho Nacional de Secretarias Municipais de Saúde), apoiador-SES e todas as combinações possíveis. As que se destacaram com evidências de 
problematização, mobilização e construção de alianças foram: apoiador-apoiador temático; apoiador-UGP; apoiador-Grupo Condutor, objeto principal desta análise. É necessário frisar que essa escolha não se deu apenas pela frequência com que as questões foram problematizadas, mas considerou $\mathrm{o}$ potencial de controvérsia, de desencadeamento de novas conexões e de consolidação das já existentes.

\section{Resultados e discussão}

Os resultados serão apresentados segundo as perguntas referenciadas nas operações de tradução, considerando os domínios de mediação como definidos por Clavier et al. (2012), ou seja, cognitivas, estratégicas e logísticas, e as múltiplas interfaces de relações dos diferentes actantes.

Nesses termos, no domínio cognitivo, os principais temas problematizados foram: a função e as competências do apoiador; e a elaboração técnica dos subprojetos e os conhecimentos específicos sobre regionalização e RAS. Essas questões se distribuíram pelos três domínios de mediação.

As conexões, ou relações entre actantes, mobilizadas para encaminhar controvérsias e convergências vinculadas à competência dos apoiadores, ocorreram principalmente na interface entre os apoiadores e os GC, mobilizando-se, inclusive, apoiadores de redes temáticas - Redes de Urgência e Emergência (RUE), Cegonha, Psicossocial, Humanização, Indígena e Atenção Básica. Adicionalmente, a UGP foi acionada para facilitar o entendimento e limites de atuação desses atores. Essa última conexão se configurou prioritariamente, nos momentos de desarticulação dos GC relacionados às alternâncias de poder nos municípios. A articulação entre os apoiadores das 15 regiões foi fomentada, na primeira fase do projeto, pela função coordenadora do Departamento de Articulação de Redes de Atenção à Saúde (Daras/MS), que apoiava e supervisionava essas atividades. Após a extinção desse Departamento em 2013, as interfaces apoiador-apoiador temático e apoiador-UGP passam a concentrar as operações de translação. As interconexões entre apoiador-UGP ocorreram com foco na disponibilização de suporte técnico aos locais e de legitimação da atuação do apoiador junto às instâncias estaduais e municipais, dentre as quais as SES e Conasems. As conexões apoiador-GC foram afetadas pelas diversas alternâncias de poder e consequentes mudanças nas secretarias municipais de saúde, implicando a desestruturação provisória dos GC. Tal cenário instável explicitou claramente o quão as conexões apoiador-GC eram essenciais para a mediação logística da implementação. As desarticulações temporárias dos GC, em alguns casos durante seis meses, concorreram para a interrupção de processos licitatórios e de diversos arranjos de intermediação com a instituição financiadora.

O processo de mobilização para acordar as competências do apoiador e seus limites foi diversificado nos diferentes locais, envolvendo, primordialmente, as articulações de parcerias. Os apoiadores das redes temáticas, por exemplo, da RUE, da Rede Cegonha, da Saúde Indígena e da Psicossocial, foram os principais interlocutores. Alguns mecanismos foram mobilizados para a materialização das alianças entre apoiadores do QSR e os das redes temáticas na medida em que a convergência de competências entre eles facilitava a harmonização de processos de trabalho comuns. Relatos dos apoiadores ilustram essas conexões: "Fui pra dentro do Grupo Condutor de redes". A atividade do apoiador por região envolvia a possibilidade de integrar

um especialista na região e um generalista para pensar na região de saúde, pensar a rede, pensar o Coap [Contrato Organizativo da Ação Pública da Saúde], enfim, pensar em todas as coisas que têm interseção entre si. (APOIADORA LOCAL 23902B). 
O segundo tema problematizado, a elaboração técnica e adequação dos subprojetos, compreendeu dois eixos. O primeiro deles se refere a conteúdos cognitivos do âmbito da técnica. Esses conteúdos envolveram conhecimentos, competências e habilidades para responder a requisitos estabelecidos pelo financiador do projeto. Vale ressaltar que a adequação entre tais exigências e o contexto local demandou suporte técnico, de coordenação e de articulação, expandindo a construção de conexões além do cognitivo e abrangendo o domínio estratégico de translação. Exemplo dessas conexões foi o acionamento de apoio técnico da UGP/MS para a composição dos Planos de Aquisição dos insumos necessários à implementação dos projetos e dos processos licitatórios pertinentes. O segundo eixo problematizado referiu-se a conteúdos técnicos específicos das prioridades e ações dos subprojetos. A necessidade de mobilização de consultores externos para subsidiar soluções de implantação do transporte sanitário, por exemplo, ocorreu em todos os subprojetos que priorizaram esse componente. Em apenas um deles, a conexão se inscreveu como uma parceria.

O domínio cognitivo sobre a temática de regionalização e RAS emergiu em diferentes temas, ou seja, como um conteúdo transversal. Assim, o conhecimento necessário para o estabelecimento das competências do apoiador envolvendo a compreensão dos processos inerentes à organização interfederativa do SUS constituiu-se como um pré-requisito comum a todas as ações e propostas dos subprojetos. Nesse sentido, uma grande variedade de temáticas foi identificada como prioritárias tais como: modalidades e instrumentos de governança, Coap, programação pactuada e consorciada, para citar alguns.

A mobilização para elaboração desses conteúdos vinculou-se a alguns fatores. Por exemplo, o prévio engajamento local com ações relativas à temática da regionalização, e a execução de iniciativas de capacitação, realização de oficinas e seminários.
Ressalte-se que, em alguns casos, esses momentos foram utilizados como espaços de compartilhamento e atualização do processo de implementação dos subprojetos, como no exemplo a seguir:

Porque, no GC, tínhamos pessoas com perfil difícil, que não estavam colaborando, pessoas críticas, que não estavam acreditando em mudanças. E o processo de implantação de redes precisa muito de pessoas com resiliência, com disposição para mudar e para entender o processo do sistema. Então, como tinha essa consultoria, esses encontros de fevereiro a dezembro (GC) para fazer os momentos das oficinas de gestão de pessoas; antes disso havia uma fala de atualização, mas uma fala breve e tentando correr com os processos: contratação de empresas de eventos, aquisição de veículos etc. (APOIADORA LOCAL 23902A).

Chama à atenção o fato de a grande maioria dos subprojetos na sua configuração inicial privilegiava a qualificação das equipes profissionais das redes de atenção, numa relação explícita entre qualificação de rede e melhoria da capacidade técnico-profissional. É significativo assinalar que a concepção de qualidade da gestão pública nos processos atuais de reforma do Estado é predominantemente vinculada à ideia de eficiência, ou rendimento, que pressupõe a qualificação técnica. É importante ressaltar que não só a eficiência como as concepções tradicionalmente articuladas ao desempenho de sucesso de uma gestão pública estão ancoradas na afiliação das políticas públicas onde se insere a gestão, estando, portanto, intimamente ligadas a modelos de proteção social. Em outras palavras, o exame da qualidade da gestão não pode ocorrer dissociado da apreciação do modelo de proteção social subjacente (LOBATO, 2012; FLEURY; OUVERNEY, 2012).

Outro ponto de controvérsia foi o processo de regionalização. O projeto QSR não adotou em todas as localidades a espacialização política e geográfica já definida pela regionalização local. A reconfiguração de 
algumas regiões envolvidas gerou sobretrabalho e responsabilidades adicionais ao corpo técnico participante. Considerando a organização regional do QSR, dois outros problemas de ordem política ocorreram: a acomodação às coalizões políticas locais e a harmonização do projeto com a concepção de regionalização preconizada pelo SUS. Esta última foi enfatizada com veemência pela representação do Conselho Nacional de Secretários de Saúde (Conass), como descrito a seguir:

O conflito maior foi na definição das regiões, porque a gente - Conass - defendia uma coisa, Conasems e MS outra, aí teve vários embates, três ou quatro reuniões para definir porque para mim ele - QSR- tinha que estar casadinho com as redes que estão sendo implantadas. Então vejo como uma coisa que anda no paralelo, fragmentado. (REPRESENTANTE CONASS).

Destaca-se o caráter provisório de algumas conexões que se esgotaram na resolução do tema problematizado, enquanto outras se caracterizaram por inscritos (LATOUR, 2002), revelando interações duráveis e viabilizando a implementação de alguns subprojetos. Os quadros 2, 3 e 4 sintetizam, por domínios de mediação, as questões problematizadas e os modos de mobilização e inscritos de alianças.

Quadro 2. Temas problematizados, operações de tradução e categorias de mediação cognitiva

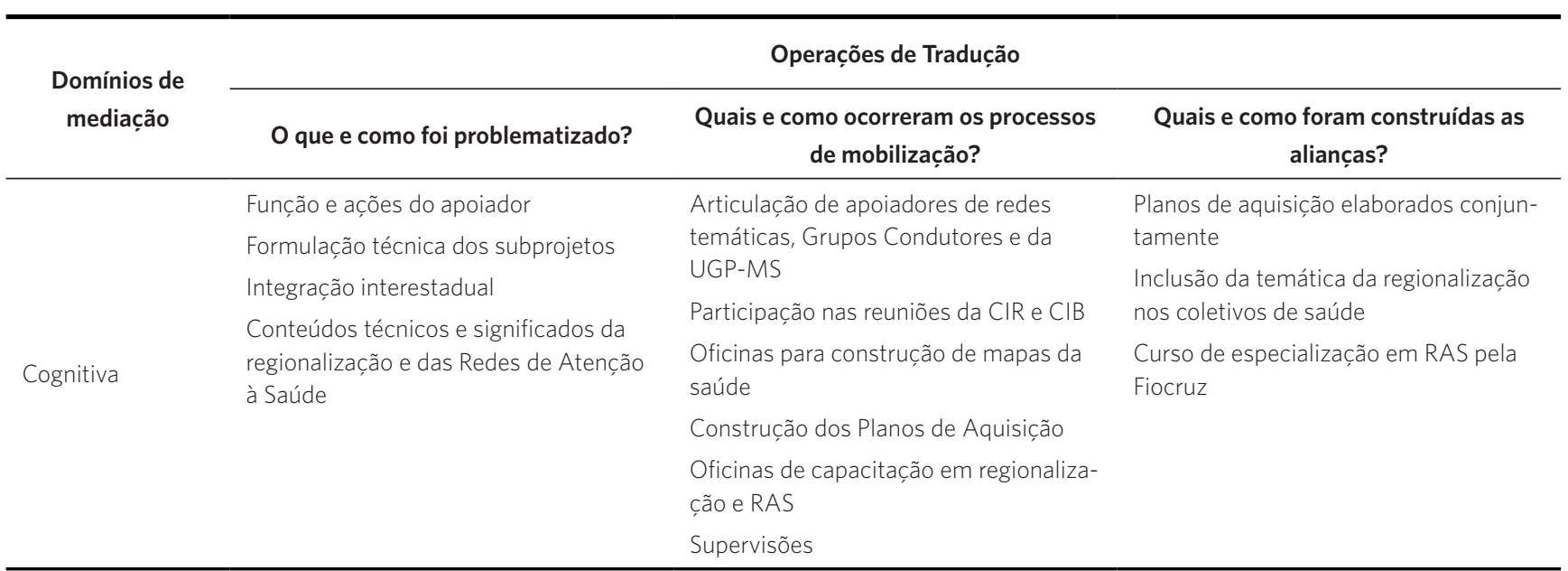

Na dimensão estratégica, um tema problematizado que se destacou pela baixa visibilidade durante a execução do projeto foi o da participação social. Vários apoiadores enfatizaram a prioridade dada às questões técnicas do subprojeto em detrimento da construção de redes de apoio social que possibilitassem legitimidade e sustentabilidade à iniciativa. A presença das universidades foi pontual e não há referências significativas à inclusão de representações dos movimentos sociais e de organizações da sociedade civil local. Como descrito em Latour (1996), um ponto de passagem importante na construção de alianças é a identificação comum entre os actantes. Evidência interessante das operações de mobilização foi a criação de e-mail próprio do GC, desvelando uma relação de pares relatada em um dos casos. 
Quadro 3. Temas problematizados, operações de tradução e categorias de mediação estratégica

\begin{tabular}{|c|c|c|c|}
\hline \multirow{2}{*}{$\begin{array}{l}\text { Domínios de } \\
\text { mediação }\end{array}$} & \multicolumn{3}{|c|}{ Operações de Tradução } \\
\hline & O que e como foi problematizado? & $\begin{array}{l}\text { Quais e como ocorreram os processos } \\
\text { de mobilização? }\end{array}$ & $\begin{array}{l}\text { Quais e como foram construídas as } \\
\qquad \text { alianças? }\end{array}$ \\
\hline \multirow{10}{*}{ Estratégia } & $\begin{array}{l}\text { Composição das diversas fontes de } \\
\text { apoio técnico para viabilizar as diretrizes } \\
\text { da instituição financiadora e do MS }\end{array}$ & $\begin{array}{l}\text { Apoio técnico da UGP-MS acionado por } \\
\text { meio de reuniões e consultorias presen- } \\
\text { ciais e virtuais }\end{array}$ & $\begin{array}{l}\text { Aliança entre apoiador e UGP espe- } \\
\text { cialmente por meio da designação de } \\
\text { expertise apropriada, expressando a }\end{array}$ \\
\hline & Baixo consenso na atribuição de prio- & \multirow{3}{*}{$\begin{array}{l}\text { Articulação com as CIR e CIB para for- } \\
\text { malização de consensos, mais evidentes } \\
\text { nas regiões interestaduais }\end{array}$} & colaboração entre apoiador-UGP \\
\hline & & & \multirow{2}{*}{$\begin{array}{l}\text { Regimento interno interestadual na } \\
\text { região elaborado }\end{array}$} \\
\hline & Mudança do modelo de atenção & & \\
\hline & Regiões interestaduais & $\begin{array}{l}\text { Realização de oficinas sobre mudanças } \\
\text { no modelo de atenção }\end{array}$ & $\begin{array}{l}\text { Fluxo do Serviço de Oncologia da região } \\
\text { desenhado }\end{array}$ \\
\hline & \multirow{5}{*}{ Participação social } & Diagnóstico situacional & Consultoria especializada em RAS \\
\hline & & $\begin{array}{l}\text { Articulação com apoiadores temáticos e } \\
\text { elaboração interestadual do subprojeto }\end{array}$ & $\begin{array}{l}\text { Realização de oficinas multi-institucio- } \\
\text { nais (MS, Conass e Conasems) }\end{array}$ \\
\hline & & $\begin{array}{l}\text { Revitalização do GC com criação de } \\
\text { e-mail próprio }\end{array}$ & $\begin{array}{l}\text { Subprojeto pactuado nas CIR, CIB e } \\
\text { encaminhado ao MS }\end{array}$ \\
\hline & & \multirow{2}{*}{$\begin{array}{l}\text { Inclusão das instâncias representativas } \\
\text { do SUS, Conselhos de Secretarias Muni- } \\
\text { cipais de Saúde (Cosems), Conass }\end{array}$} & $\begin{array}{l}\text { Construção do grupo de trabalho para } \\
\text { operacionalizar as decisões do GC }\end{array}$ \\
\hline & & & $\begin{array}{l}\text { Inclusão temporária de universidades } \\
\text { em subprojetos }\end{array}$ \\
\hline
\end{tabular}

A compreensão da mediação logística supõe reflexão retrospectiva sobre o manejo da relação entre o processo de planejamento e a implementação em cada subprojeto. O planejamento consumiu uma parcela importante do tempo previsto de duração do QSR. A maioria dos subprojetos subestimou os processos envolvidos na mobilização e construção de alianças necessárias à implementação dos componentes técnicos pertinentes.

Os limites de autonomia e poder decisório foram fator dificultador da logística da implementação. A conexão apoiador-GC foi interrompida em diversos subprojetos, requerendo mobilização para a sua recomposição. Destaca-se como ferramenta de utilidade a modelização das intervenções consolidadas nos Modelos Lógicos (ML) previamente pactuados (COUSINS; CHOUINARD, 2012). A representação comum entre pares da intervenção, por meio dos $\mathrm{ML}$, viabilizou a comunicação com novos atores e parceiros mobilizados no processo de recomposição dos GC. 
Quadro 4. Temas problematizados, operações de tradução e categorias de mediação logístico

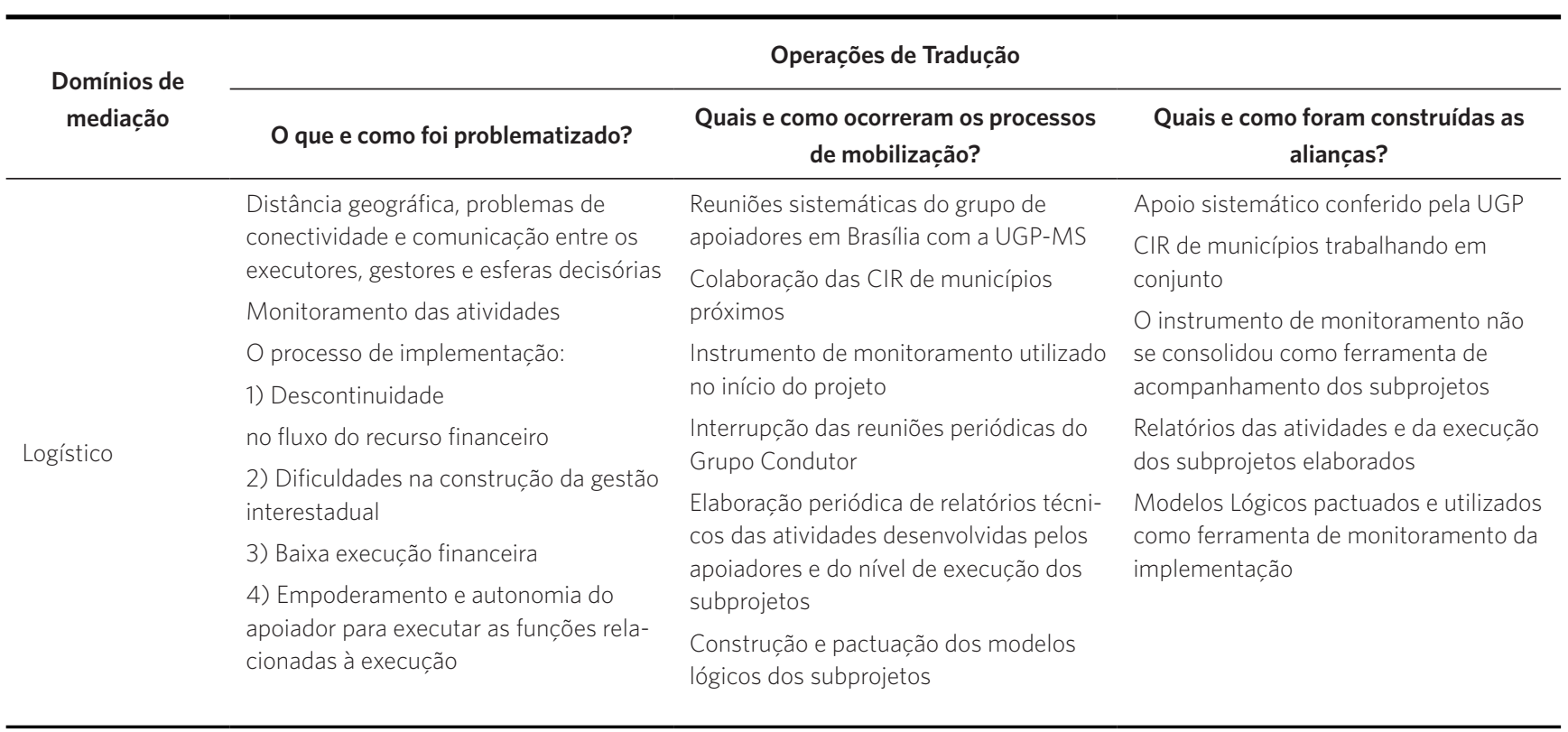

\section{Conclusões}

$\mathrm{O}$ envolvimento de quinze locais com contextos diferenciados e intervenções específicas prenunciava uma grande possibilidade de conexões. Entretanto, as conexões identificadas, apesar de alguma diversificação, se restringiram a opções usualmente mencionadas nas iniciativas induzidas pelo MS na operacionalização de diretrizes que requeiram a articulação interfederativa, frequentemente privilegiando como 'caixa pretas' as soluções e ações técnicas. Exemplo disso são os processos de mobilização que se repetem ao longo dos diversos domínios de mediação, tais como as capacitações técnicas, a compatibilização de normas e leis e o envolvimento das instâncias de representação e deliberação (Comissão Intergestores Regional - CIR, Comissão Intergestores Bipartite - CIB, Conasems). Essas evidências confirmariam a existência das controvérsias sobre a função apoiador entre os diferentes actantes envolvidos na sua implementação. Mas algumas exceções merecem destaque. No domínio cognitivo, a utilização dos espaços de capacitação como momentos de otimização e discussão dos subprojetos. Na mediação estratégica, chamam a atenção os movimentos de articulação interestaduais, inclusive com a criação de regimento específico para modular o funcionamento dessa parceria. Do ponto de vista logístico, é interessante ressaltar a emergência dos ML como ferramenta de integração.

Algumas conexões foram expressivas nos três domínios de mediação, dentre elas, a estabelecida entre apoiadores QSR e apoiadores temáticos. Embora já existisse no projeto a indução de uma rede de apoiadores QSR, a relação dessa rede com os apoiadores temáticos parece ter emergido da prática comum nas regiões. Essa interação contém indícios de institucionalização da função apoio. Nesse caso, uma rede dentro da rede. Se quisermos concluir, teremos que considerar como os apoiadores 'engenheiros de conexão' desenvolveram operações de translação capazes de "engatar outra marcha e mudar a [...] controvérsia de um domínio para outro" (LATOUR, 2011, P. 347).

Dois contextos merecem destaque por 
evidenciarem operações de mobilização e construção de alianças bastante particulares. Os subprojetos interestaduais e aqueles ocorridos em regiões de fronteira com população indígena. As articulações entre municípios próximos, no caso de subprojetos interestaduais, configuraram alianças que mimetizam os consórcios para organizações interestaduais de serviços, acomodando as dificuldades oriundas do processo de legitimação nas esferas estaduais específicas. Por exemplo, a aprovação em instâncias como CIR, CIB, Conasems nos diferentes estados envolvidos. Nas regiões de fronteira com população indígena, a inclusão de representantes desses interesses nos GC ocorreu tardiamente, durante o processo de planejamento das ações, implicando a reformulação de subprojetos nessas regiões.

Em relação a possíveis conexões buscando a mitigação da descontinuidade dos recursos do projeto, a função dos apoiadores foi bastante restrita, seja por desconhecimento dos trâmites envolvidos seja pela não legitimação de sua função propositiva na resolução do problema.

Destaca-se a dificuldade de manejo de tempo para viabilizar a produção e o fortalecimento de conexões revelada no descompasso entre o desprendido na fase do planejamento e o necessário para a sua implementação. Essa evidência pode indicar hipóteses interessantes para estudos posteriores, tematizando a utilização de modelos de monitoramento e avaliação participativos para a gestão.

Tanto no que se refere ao papel como às competências do apoiador, poder-se-ia propor a ampliação de sua vinculação aos movimentos sociais e à comunidade local. Esses vínculos certamente contribuiriam para a ampliação da rede de actantes, fortalecendo as conexões já existentes com as instâncias decisórias do SUS (apoiador-CIR/ CIB/Conasems). Na visão de Latour (2011), esses actantes poderiam ser indispensáveis ao se tornarem ponto de passagem obrigatório para aqueles que quisessem promover seus interesses. Muitas vezes, tais interesses significam alistar atores não humanos, ou actantes, a fim de mobilizar e enredar os atores humanos.

Consequentemente, a legitimação da função apoio como uma unidade organizacional, embora com pouca autonomia gerencial e nenhuma financeira, diluiu a possibilidade desses actantes construírem correlações de forças para o enredamento, mobilização e composição de alianças na resolução de conflitos e controvérsias. Em última análise, a problematização, a mobilização e a construção de alianças ocorreram em situações contextualizadas. As conexões nelas implicadas exigiram ações também contextualizadas e, muitas vezes, limitadas.

\section{Agradecimentos}

Agradecemos em particular à Profa. Louise Potvin da Universidade de Montréal pelas importantes sugestões aportadas quando do desenho inicial do artigo e apresentação do modelo teórico adotado nesta análise. 


\section{Referências}

APOIADORA LOCAL [23902a]. QualiSUS-Rede. Brasília, DF, 17 de set. 2014. Entrevista concedida a CARDOSO, G.; CUNHA, C. L. F. para o Projeto Avaliação de Implementação do Projeto de Formação e Melhoria da Qualidade da Rede de Atenção à Saúde (QualisUS-Rede). MP3.

APOIADORA LOCAL [23902b]. QualiSUS-Rede. Brasília, DF, 17 de set. 2014. Entrevista concedida a CARDOSO, G.; CUNHA, C. L. F. para o Projeto Avaliação de Implementação do Projeto de Formação e Melhoria da Qualidade da Rede de Atenção à Saúde (QualisUS-Rede). MP3.

BOWEN, S.; ZWI, A. B. Pathways to 'evidenceinformed' policy and practice: a framework for action. PLoS medicine, San Francisco, v. 2, n.7, p. 600-5, 2005.

BRASIL. Ministério da Saúde. Apoio integrado à gestão descentralizada do SUS: apoiador: experiências partilhadas, soluções coletivas. Brasília, DF: MS; OPAS, 2005.

. Ministério da Saúde. Coordenação-Geral de Cooperação Interfederativa. Diretrizes para o apoio integrado à gestão interfederativa do SUS. Brasília, DF: Ministério da Saúde, 2013. Disponível em: <https:// central3.to.gov.br/arquivo/240606/>. Acesso em: 27 jan. 2016.

Ministério da Saúde. Secretaria-Executiva. Caderno de referência para o processo de formação de profissionais do apoio institucional integrado do Ministério da Saúde. Brasília, DF: Ministério da Saúde, 2011a. (Série F. Comunicação e Educação em Saúde).

Ministério da Saúde. Secretaria Executiva. Portaria ${ }^{0} 396$, de 4 de março de 2011. Institui o Projeto de Formação e Melhoria da Qualidade de Rede de Saúde (Quali-SUS-Rede) e suas diretrizes operacionais gerais. Diário Oficial [da] União, Brasília, DF, 2011b. Disponível em: <http://bvsms.saude.gov.br/ bvs/saudelegis/gm/2011/prt0396_04_03_2011.html>. Acesso em: 27 jan. 2016.
CALLON, M. Power, action and belief: a new sociology of knowledge? In: BIAGIOLI, M. (Ed.). The Science Studies Reader. Londres: Routledge, 1986, p.196-223.

CALLON, M.; LATOUR, B. Unscrewing the big Leviathan: how actors macro-structure reality and how sociologists help them to do so. In: KNORR-CETINA, K.; Cicourel, A. V. (Ed.). Advances in social theory and methodology: toward and integration of micro- and macro-Sociologies. Boston: Routledge; Kegan Paul, p. 277-303. 1981

CASANOVA, A. O.; TEIXEIRA, M. B.; MONTENEGRO, E. O apoio institucional como pilar na cogestão da atenção primária à saúde: a experiência do Programa TEIAS - Escola Manguinhos no Rio de Janeiro, Brasil. Ciência \&t Saúde Coletiva, Rio de Janeiro, v. 19, n. 11, p. 4417- 4426, nov. 2014.

CASTELLS, M.; CARDOZO, G. A sociedade em rede: do conhecimento à ação política: debates. In: (Org.). A sociedade em rede do conhecimento à acção política. Lisboa: Imprensa Nacional Casa da Moeda, 2015 .

CLAVIER, C. et al. A theory-based model of translation practices in public health participatory research. Sociology of Health \& Illness, Oxford, v. 34, n. 5, p.791$805,2012$.

COUSINS, J. B.; CHOUINARD, J. A. Participatory evaluation up close: an integration of research-based knowledge. Ottawa: University of Ottawa, 2012.

DE LEEUW, E. D. et al. (Ed.). The International Handbook of Survey Methodology. Nova York: Erlbaum; Londres: Taylor \& Francis, 2008.

FLEURY, S.; OUVERNEY, A. L. L. Gestão de redes: a estratégia de regionalização da política de saúde. Rio de Janeiro: FGV, 2011.

O Sistema Único de Saúde brasileiro: desafios da gestão em rede. Revista Portuguesa e Brasileira de Gestão, Lisboa, v. 11, n. 2-3, p. 74-83, 2012. 
FREEMAN, R. E.; WICKS, A. C.; PARMAR, B. Stakeholder Theory and "The Corporate Objective Revisited”. Organization Science, Catonsville, v. 15, n. 3 , p. 364-369, maio/jun. 2004.

FREIRE, P. Conscientização. São Paulo: Cortez, 2016.

GAGNON, M. L. Moving knowledge to action through dissemination and exchange. Journal of Clinical Epidemiology, v. 64, n.1, p. 25-31, 2011. Disponível em: <http://dx.doi.org/10.1016/j.jclinepi.2009.08.013>. Acesso em: 29 abr. 2016.

GRANOVETTER, M. The strength of weak ties. American Journal of Sociology, Chicago, v. 78, n. 6, p. 1360-80, 1973.

LATOUR, B. On actor-network theory: a few clarifications plus more than a few complications, Sziale Welt, Baden-Baden, v. 47, p. 369-81, 1996.

A prologue in form of a dialog between a student and his (somewhat) socratic professor. 2002. Disponivel em: <http://www.bruno-latour.fr/articles/article/090. html>. Acesso em: 20 abr. 2016.

Re-assembling the social: an introduction to Actor-Network Theory. Oxford: Oxford University Press, 2005.

. Ciência em ação. São Paulo: Unesp, 2011.

LAW, J.; HASSARD, J. Actor network theory and after. Massachusetts: Blackwell; Sociological Review, 1999.

LOBATO, L. V. C. Políticas sociais e de saúde: temas fundamentais da reforma sanitária. Coleção Cidadania para a Saúde. Rio de Janeiro: Cebes, 2012.

MENDES, E. V. As redes de atenção à saúde. Brasília, DF: OPAS, 2011.

NAY, O.; SMITH, A. Les intermediaires en politique: mediation et jeux d'institutions. In: (Ed.). $L e$ gouvernement du compromis: courtiers et généralistes dans l'action politique. Paris: Economica, 2002.

PAULON, S. M. et al. Apoiar, intervir e agenciar: dos diferentes usos dos dispositivos da Política Nacional de Humanização na perspectiva dos apoiadores em formação. Saúde Transform. Soc., Florianópolis, v. 5, n. 2, nov. 2014.

PRELL, C. Social network analysis: history, theory and methodology. London: SAGE, 2012.

\section{PROJETO AVALIAÇÃO DE IMPLEMENTAÇÃO} DO PROJETO DE FORMAÇÃO E MELHORIA DA QUALIDADE DA REDE DE ATENÇÃO À SAÚDE (QUALISUS-REDE). Relatório final. Laboratório de Avaliação de Situações Endêmicas Regionais, Escola Nacional de Saúde Pública Sérgio Arouca, Departamento de Endemias Samuel Pessoa, Fundação Oswaldo Cruz. Rio de Janeiro, Dezembro, 2015.

SANTOS, E. M. et al. Monitoramento em promoção de saúde: uma experiência de capacitação de adultos em um estado do Nordeste brasileiro. Educar em Revista, Curitiba, n. 46, p. 193-207, out./dez. 2012.

Recebido para publicação em abril de 2016

Versão final em outubro de 2016

Conflito de interesses: inexistente

Suporte financeiro: não houve 